\title{
Avoidance behavior in rats with lesions in the septum, fornix longus, and amygdala
}

\author{
JACQUELINE C. BRESNAHAN, PATRICIA M. MEYER, ROGER B. BALDWIN, \\ and DONALD R. MEYER \\ Laboratory of Comparative and Physiological Psychology, \\ The Ohio State University, Columbus, Ohio 43212
}

\begin{abstract}
Normal rats and rats with lesions of the septum, amygdala, and fornix longus were tested on a passive avoidance task in an apparatus with an alternate escape route. Avoidance behavior was measured continuously for a 2-min test interval. Subjects with septal lesions failed to avoid passively; those with amygdaloid lesions were hyperexploratory and showed no avoidance preferences; those with fornix longus lesions actively retreated from the food-shock area; and normal control animals initially passively avoided, but subsequently actively retreated from the food-shock area. The results are discussed in terms of alterations in locomotor behavior and in motivational properties of the stimuli.
\end{abstract}

One of the early studies investigating avoidance behaviors following lesions in the limbic system was performed by McCleary (1961). Cats were subjected to lesions in the subcallosal-septal area or to ablations of the cingulate cortex. These regions had previously been defined electrophysiologically as producing, respectively, inhibition and facilitation of ongoing responses (Kaada, 1951). The animals in the McCleary study were trained on a conditioned avoidance habit (CAR) and on a passive avoidance task (PA). To perform efficiently on the CAR, the cats' best strategy was to move quickly to the opposite compartment in response to a conditioned stimulus (CS) to avoid shock. In the case of PA, however, inhibition of movement was required to successfully avoid shock. The results, for the most part, confirmed his predictions and could be correlated with the electrophysiological results. Those cats with lesions of the subcallosal gyrus-septal region, indeed, were facilitated in learning the CAR, but could not inhibit responding during PA testing. On the other hand, cats with damage in the cingulate cortex were not impaired on PA, but required more trials to learn the CAR than normal animals.

These changes in avoidance behaviors following surgery might be attributed to alterations in locomotor behavior. For example, increased locomotor

This research was supported, in part, by Grant MH-06211 from the National Institute of Mental Health to Donald R. Meyer and Patricia M. Meyer while the first author was a Predoctoral Fellow supported by Training Grant MH-06748 from the United States Public Health Service. Patricia M. Meyer is a U.S. Public Health Service Research Scientist Development Investigator (5-Ka-MH-12, 747) of the National Institute of Mental Health. The first author is presently in the Department of Anatomy at The Ohio State University. Requests for reprints should be sent to Patricia M. Meyer, The Ohio State University Research Center, Laboratory of Comparative and Physiological Psycholgy, 1314 Kinnear Road, Columbus, Ohio 43212. responses could result in facilitated CAR performance and deficits in PA performance. Alternatively, alterations in the motivational properties of the stimuli could contribute to the observed changes in avoidance behavior. Decreased value of aversive stimuli could lead to a deficit in performance on both CAR and PA tasks. Consequently, Ursin, Linck, and McCleary (1969) attempted to determine what role these two possible factors might play in the observed changes in avoidance behaviors following surgery. They used an apparatus designed by Maher, Elder, and Noblin (1962) to dissociate the effects of locomotor and motivational variables on PA performance. The apparatus had two runways. In one runway, the subject was reinforced and then punished (typical PA paradigm), and in the other runway, the subject was never reinforced or punished. Thus, on testing for PA behavior, the animal could passively avoid by remaining immobile in a startbox or could move into a neutral alley exhibiting locomotor behavior without suffering the consequences of approaching an area in which it had been shocked (as is the case in the normal PA situation). On the other hand, the subject could move into the reinforced and punished area, demonstrating a PA deficit which would be unrelated to an inability to freeze or an inability to inhibit locomotor behavior. Ursin et al. found that subjects with septal lesions tended to return to the goalbox where they previously had been shocked. Normal rats and rats with cingulate lesions preferred not to avoid passively by remaining immobile, but they actively retreated from the reinforced and punished area into the neutral alley. Thus, the septal preparations perseverated in the previously learned approach response, indicating a motivational deficit rather than an inability to inhibit locomotor responses, per se.

In the present experiment, we trained rats with lesions of the septum, amygdala, and fornix longus 
(a major pathway between the septum and the hippocampus) in the Maher et al. (1962) apparatus, which permitted a continuous time measure of PA. Even though prior research has indicated that removal of the septum and amygdala result in PA deficits, as measured by discrete trial procedures (Kaada, Rasmussen, \& Kveim, 1962; Pellegrino, 1968), we were interested in examining these preparations, as well as those with fornix longus lesions, in an attempt to better specify the behavioral characteristics of shock avoidance.

\section{METHODS}

\section{Subjects}

Forty-six Long-Evans male hooded rats, between 90 and 120 days old, served as subjects. They were housed individually in wire cages and were maintained on a 23-h food-deprivation schedule beginning 5 days prior to apparatus adaptation and continuing throughout the experiment. The rats were randomly divided into one of the following groups and underwent surgery as indicated: Group N, normal control; Group S, septal lesion; Group A, amygdaloid lesion; Group F, lesion of fornix longus. Only those subjects reaching criterion on the approach task were included in the study.

\section{Surgery}

The subjects were anesthetized intraperitoneally (IP) with pentobarbital sodium $(60 \mathrm{mg} / \mathrm{kg})$. Some animals received half of this dosage and were supplemented with methoxyflouride (Meyer \& Meyer, 1972). Atropine sulfate was also injected (IP) to inhibit mucous secretion. Electrolytic lesions were made with a unipolar electrode, uninsulated $0.5 \mathrm{~mm}$ at the tip, and the circuit was completed via an anal anode. The stereotaxic coordinates, computed with reference to the deGroot (1959) atlas were as follows: septal, $\mathrm{AP}+7.8 \mathrm{~mm}, \mathrm{DV}+1.0 \mathrm{~mm}, \mathrm{~L} \pm$ $0.5 \mathrm{~mm}$; amygdala, $\mathrm{AP}+4.2, \mathrm{~L} \pm 5.0, \mathrm{DV}-3.0$, and $\mathrm{AP}$ 5.0, $\mathrm{L} \pm 4.5, \mathrm{DV}-3.0$, and $\mathrm{AP}+5.8, \mathrm{~L} \pm 4.5$ and $\mathrm{DV}-2.5$; fornix, AP + $6.4 \mathrm{~mm}, \mathrm{DV}+2.4 \mathrm{~mm}, \mathrm{~L} 0.0 \mathrm{~mm}$. Postsurgically, a broad-band antibiotic was administered for prophylactic purposes, and the animals were allowed a 2-day recovery period.

\section{Apparatus}

The apparatus, similar to that described by Ursin et al. (1969), is illustrated in Figure 3 (left side). It was divided into nine segments, each of which was $30 \mathrm{~cm}$ long and $30 \mathrm{~cm}$ high. The startbox (Segment 5) was $30 \mathrm{~cm}$ wide. It was located in the center of two alleys (Segments 2, 3, 4 and 6, 7, 8), which were $25 \mathrm{~cm}$ wide and opened into two goalboxes (Segments 1 and 9), which were $30 \mathrm{~cm}$ wide. A small restraining box $(8 \times 12 \times 10 \mathrm{~cm})$ was used to confine the subject for $30 \mathrm{sec}$ prior to the daily procedure and for the intertrial intervals (ITI $=30 \mathrm{sec}$ ) during training and testing. This small box was placed in the startbox in the center of the apparatus, and the subject was released at the appropriate time by raising a guillotine door on one side of the restraining box. One alley and goalbox were painted flat white and the other alley and goalbox were painted flat black. The startbox was painted neutral gray. Steel grids made up the floors of the goalboxes. Each goalbox contained a small glass dish fitted with a metal plate. Thus, the animal could receive both foot and mouth shock as it ate wet mash. Two light sources $(71 / 2-W$ light bulbs) were suspended above the center of each alley of the apparatus.

\section{Procedure}

The rats were placed on a food-deprivation schedule 3 days prior to surgery, and continued on that schedule for the duration of the experiment. The subjects were given access to food in their home cages for $1 \mathrm{~h}$ immediately after each daily session. Water was available in the home cages at all times.

On the third day postoperatively, all groups were adapted to the apparatus. The subjects were placed in the startbox for $30 \mathrm{sec}$, and then allowed access to the runway for $15 \mathrm{~min}$. Wet mash was available in the glass dish in one of the two goalboxes. Half of the subjects in each group were fed in the white goalbox and half were fed in the black goalbox. This procedure was continued for 3 days. On the subsequent day, training was begun. On each trial, the rat was released from the restraining box into the startbox section of the maze. One teaspoon of wet mash was available in the goalbox in which food had been obtained during adaptation. Alley choices were recorded when the subject had all four feet in one alley. If the animal entered the wrong alley, it was allowed to correct itself. On each trial, the latency to begin eating the food was measured as the time elapsed between being released from the restraining box and beginning to eat the food. If, within $2 \mathrm{~min}$, the subject did not begin to eat or did not find the food, the rat was returned to the start compartment for a new trial. On the first 2 days of training, 4 trials per day were given, and on the next 3 days, the animals received 6 trials per day. Thereafter, all subjects were run 10 trials per day until reaching a criterion of $9 / 10$ correct trials on 2 successive days, or $10 / 10$ correct trials on any 1 day. If the rat did not reach criterion within 15 days, training was terminated and data from that subject were not included.

Avoidance behavior was tested on the second day after reaching criterion. Trials 1 through 4 were run as in training. On Trial 5, however, the rat was shocked $(0.75 \mathrm{~mA}$ for $3 \mathrm{sec})$ through the mouth and feet when it began eating the wet mash. After the shock, the subject was immediately returned to the small startbox for a 30-sec ITI. On the next trial, the incorrect alley was blocked and the rat received a $1.4-\mathrm{mA}$ shock for $3 \mathrm{sec}$ when it began to eat the food. If, on that trial, the subject did not leave the startbox area, it was gently pushed down the alley with a paddle into the goalbox in the vicinity of the food and it received the second shock. All food and alley blocks were removed from the apparatus, and following another 30 -sec ITI, a 2 -min test period began. The rat was released from the startbox, and the experimenter recorded the animal's position in the runway every $5 \mathrm{sec}$ for $2 \mathrm{~min}$. The subject was judged to be in a segment if at least three feet were in that segment. If two feet were in each of two adjacent segments, the subject was given an intermediate score, e.g., if the subject was between Segments 3 and 4, 3.5 was recorded.

\section{Histology}

The subjects were perfused intracardially with normal saline followed by $10 \%$ Formalin while under deep anesthesia. The brains were embedded in celloidin and frontally sectioned at $30 \mu$. Every fifth section through the lesion was stained with cresylecht violet, and subsequently the sections were analyzed for the extent and locus of the lesions.

\section{RESULTS}

\section{Histology}

Reconstructions of the lesions are shown in Figures 1 and 2. An anterior, middle, and posterior section through the area of the lesion was drawn for each animal in the three experimental groups. Representative cross sections from the Pellegrino and Cushman (1967) atlas were used to draw illustrative diagrams of the lesions.

In Group F, lesions were confined, for the most part, to the fornix longus. However, in every case, minimal damage to the nucleus lateralis septi occurred. 


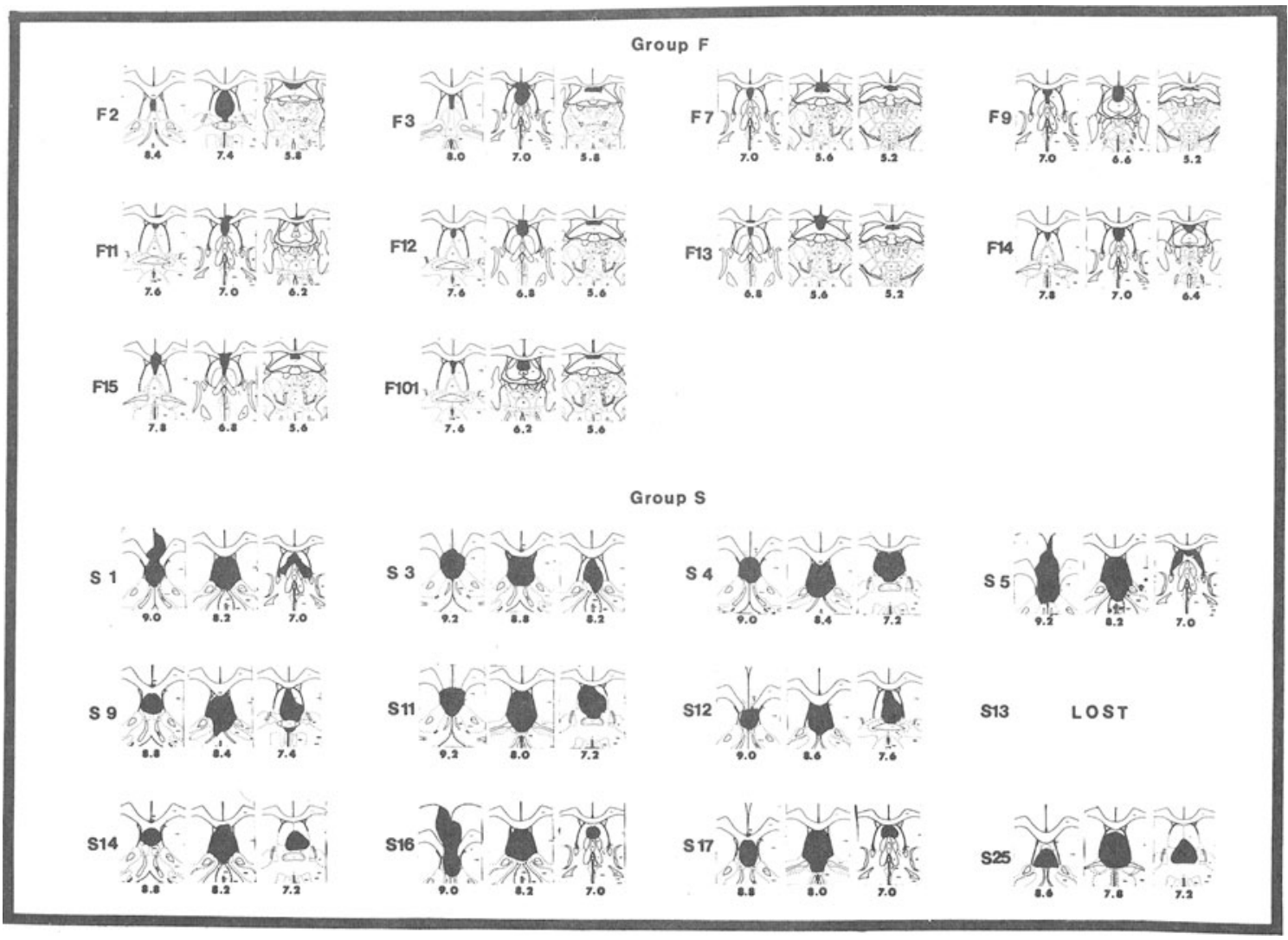

Figure 1. Anterior, middle, and posterior sections through the lesioned area for Groups $F$ and $S$.

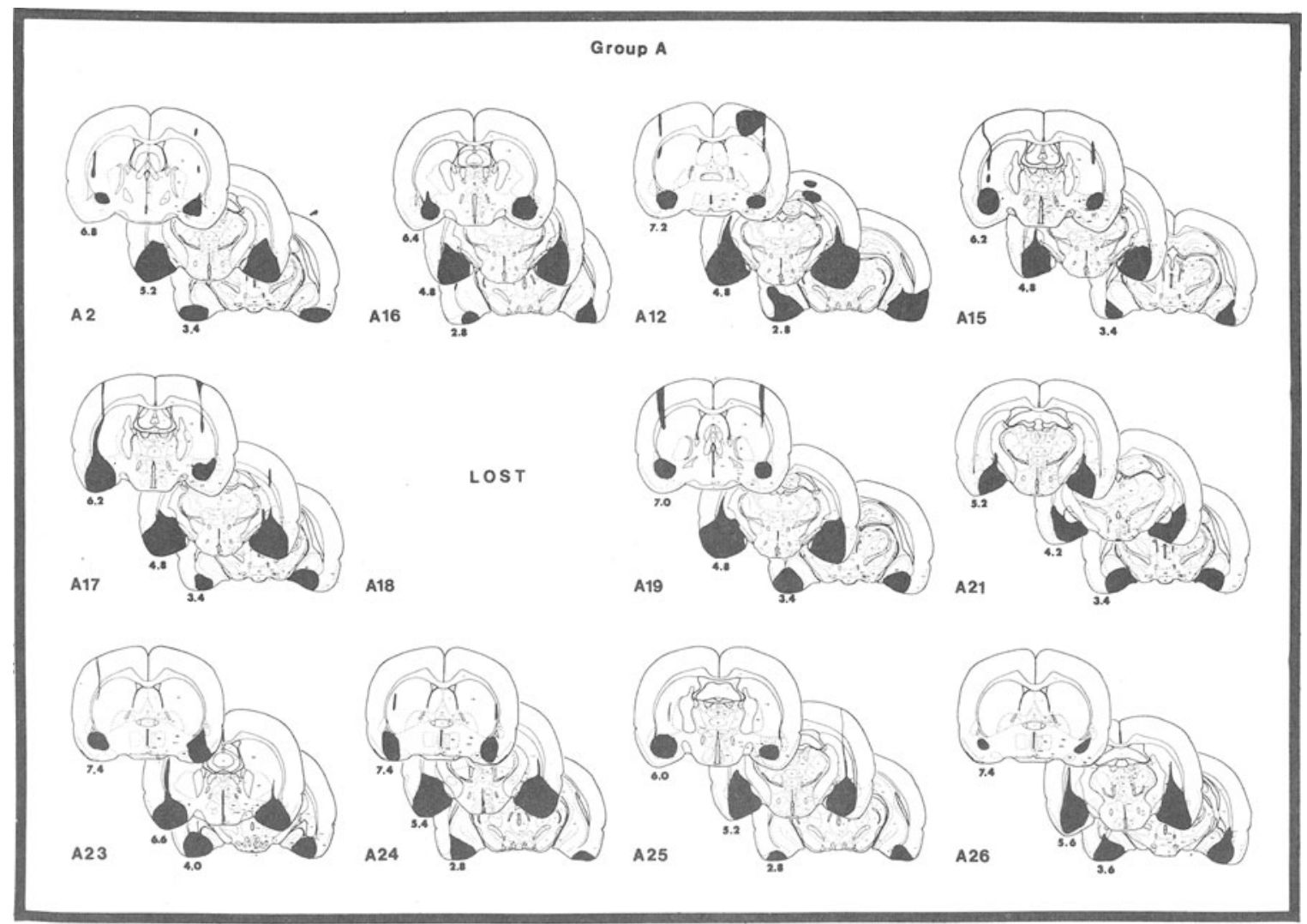

Figure 2. Anterior, middle, and posterior sections through the lesioned area for Group A. 
The fornix columna was slightly injured in F9, F14, and F101. Occasional damage also occurred to the nucleus medialis septi, nucleus triangularis septi, commissura hippocampi, cortex cingulum, and corpus callosum.

Lesions in the septum primarily involved the precommissural components. Structures damaged in the septal region were: nucleus lateralis septi, nucleus medialis septi, fornix longus, hippocampus pars anterior, and gyrus parolfactorius medialis. In six animals, the gyrus diagonalis and its nucleus were injured. Occasionally, minimal damage was observed in nucleus accumbens septi, commissura anterior, and commissura hippocampi.

Amygdaloid lesions included the following struc-. tures: nucleus amygdaloideus basalis, pars lateralis, nucleus amygdaloideus basalis, pars medialis, nucleus lateralis amygdaloideus, nucleus and amygdaloideus centralis, nucleus amygdaloideus corticalis, nucleus amygdaloideus medialis, nucleus amygdaloideus intercalatus, and cortex piriformis. In approximately half of the animals, the claustrum, stria terminalis, and area amygdaloidea anterior were damaged. All subjects had minor involvement of neocortex capsula externa, and eight, seven, and three rats had slight injury to corpus striatum, tractus opticus, and hippocampus, respectively.

\section{Trials to Learn the Approach Response}

The normal, septal, fornix, and amygdaloid groups learned the approach response to the goalbox in a median of $20,15,30$, and 50 trials, respectively. A Kruskal-Wallis one-way analysis of variance indicated significant differences among the groups $(p<.01)$. Further group comparisons, analyzed by Mann-Whitney $U$ tests, yielded the following results: Group A vs. Group S, p < .002; Group A vs. Group N, p $<.002$; Group A vs. Group F, $\mathrm{p}<.05$; Group F vs. Group N, p < .02; Group F vs. Group S, p < .002; Group S vs. Group N, n.s.

\section{Latency to Eat Food}

The latency to eat the wet mash on the correct trials of the last criterion day were also analyzed. Normal, septal, fornix, and amygdaloid groups took a median of $5.6,4.3,4.8$, and $5.4 \mathrm{sec}$, respectively. A Kruskal-Wallis one-way analysis of variance indicated no significant differences among the groups.

\section{Median Position in Alley}

Figure 3 shows the median position in the runway for all groups during each of three successive 40 -sec intervals of the 2 -min test period following shock in the food-shock segment of the alley. Kruskal-Wallis one-way analysis of variance indicated significant differences among the groups (first $40 \mathrm{sec}$, $\mathrm{p}<.001$; second $40 \mathrm{sec}, \mathrm{p}<.001$; third $40 \mathrm{sec}$, $\mathrm{p}<.001)$. Further group comparisons were analyzed by Mann-Whitney U tests.

During the first $40 \mathrm{sec}$, the normal animals tended to avoid passively and remained in the vicinity of the startbox. By the second $40 \mathrm{sec}$, they actively retreated and entered a segment of the alley never associated with either food or shock. This preference for the "safe" compartment of the alley was even stronger during the final 40 -sec interval.

In contrast, rats with septal lesions failed to avoid passively. They approached the food-shock area of the alley, and their median position during the entire 2-min test period was in segment 1-2-3. Compared to normal animals, the Septal group was severely impaired in passive avoidance during all three 40 -sec intervals $(p<.002, p<.002, p<.002$, respectively).

On the other hand, there was only a suggestion during the initial phase of testing that the Amygdaloid group failed to avoid.passively (A vs. $S=$ n.s., A vs. $\mathrm{N}=$ n.s.). By the second and third 40-sec intervals, however, rats with amygdalectomies, as indicated by median position, did passively avoid and remained in the vicinity of the startbox ( $\mathrm{S}$ vs. A, $\mathrm{p}<.02$; $\mathrm{S}$ vs. $\mathrm{A}, \mathrm{p}<.05$; second and third 40 -sec intervals, respectively). Thus, the amygdaloid impairment was only slight, and perhaps should not be viewed as an impairment at all in view of the fact that this group was not significantly different from the normal animals during any of the three $40-\mathrm{sec}$ intervals.

Animals with lesions of the dorsal fornix actively retreated throughout all three 40 -sec intervals. In fact, they retreated from the food-shock area further than the Normal group during the initial $40-\mathrm{sec}$

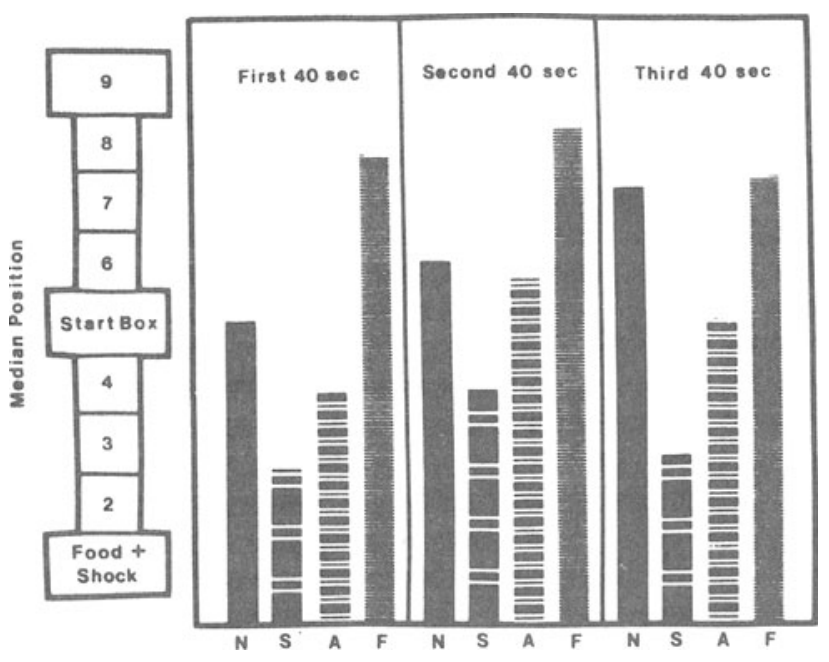

Figure 3. Median position in the runway, which is diagrammed on left, for each group during the 2 -min avoidance test period. Note that the data are presented in terms of the first, the second, and the third $40 \mathrm{sec}$ of the total $120 \mathrm{sec}$. 
interval ( $\mathrm{N}$ vs. $\mathrm{F}, \mathrm{p}<.002$ ), but by the second and third 40-sec intervals, the rats with fornix lesions could not be statistically distinguished from the normal rats. Throughout all three 40 -sec intervals, the Fornix group was significantly different from both the Amygdaloid and Septal groups. All six between-group comparisons were significant at or beyond the .05 level of confidence.

\section{Direction of First Choice}

The direction of the first movement out of the startbox during the 2-min test period (either toward the food-shock area or away from the food-shock area) was analyzed by a chi-square test. There were significant differences among the four groups $(p<.001)$. Fisher exact probability tests were used to analyze between group comparisons. Table 1 shows the number of animals in each group that initially ran in the direction they were previously shocked (approach), remained in the startbox (SB) throughout the test period, or ran in the direction opposite the shocked area (avoid).

Both the Normal and Fornix groups actively retreated from the food-shock area of the alley on their first movement out of the startbox. The animals with dorsal fornix lesions significantly differed from the Septal and Amygdaloid groups (F vs. S, p <.005; F vs. A, p < .025) in terms of their first choice preference. All but one in the Septal group failed to avoid passively, and half of the rats in the Amygdaloid group approached the food-shock segment of the alley while the other half avoided it. Initial first-choice analyses comparing the Normal group with the Septal group, and the Normal group with the Amygdaloid group revealed that the former, but not the latter, comparison was statistically significant ( $\mathrm{N}$ vs. $\mathrm{S}, \mathrm{p}<.025)$. Although more animals with septal lesions than with amygdaloid lesions failed to avoid passively on the first choice, the two groups were not significantly different from each other.

\section{Time Spent in Alley Segments}

Figure 4 illustrates the median number of 5 -sec intervals that the subjects were observed to be in each

Table 1

Number of Animals in Each Group that Approached the Goalbox in Which They Were Shocked that Passively Avoided by Remaining in the Startbox Throughout the Test Period, and that Avoided by Moving in the Opposite Direction from the Shocked Goalbox and Startbox

\begin{tabular}{lccc}
\hline Group & Approach & Startbox & Avoid \\
\hline Normal & 1 & 1 & 10 \\
Septal & 11 & 0 & 1 \\
Amygdala & 6 & 0 & 6 \\
Fornix & 0 & 0 & 10 \\
\hline
\end{tabular}

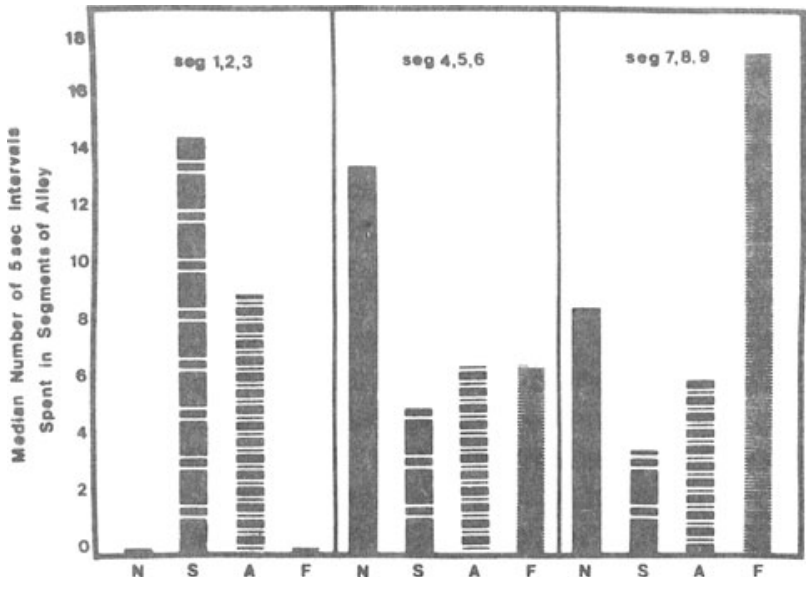

Figure 4. Median number of 5 -sec intervals spent in Runway Segments 1-2-3, 4-5-6, and 7-8-9 for each group during the 2-min test interval.

group of three alley segments (1-2-3, 4-5-6, and 7-8-9) during the 2-min test period. Kruskal-Wallis one-way analyses of variance indicated significant differences among the groups (Segments 1-2-3, $p<.001$; Segments 4-5-6, $\mathrm{p}<.02$; Segments 7-8-9, $\mathrm{p}<.01$ ). Subsequently, Mann-Whitney $U$ tests were used to make individual comparisons.

The Normal and Fornix groups spent the major percentage of time in Segments 4-5-6 $(\mathrm{N}, 57.5 \%$; $\mathrm{F}, 34.5 \%)$ or $7-8-9(\mathrm{~N}, 35.4 \% ; \mathrm{F}, 64.1 \%)$ either passively avoiding or actively retreating. In contrast the Septal group remained in Segments 1-2-3 a greater portion of the time $(60 \%)$ than in other portions of the alley $(4-5-6,22 \% ; 7-8-9,18 \%)$. The Amygdaloid group, on the other hand, divided their time approximately equally among the three areas $(1-2-3,35 \%$; $4-5-6,34.5 \%$; 7-8-9, 30.4\%).

In terms of times spent in Segments 1-2-3, the Septal and Amygdaloid groups could not be distinguished from each other statistically. Both of these groups, however, occupied the food-shock portion of the alley significantly longer than the Normal and Fornix groups (N vs. S, $p<.002 ; \mathrm{N}$ vs. A, $\mathrm{p}<.002$; $\mathrm{S}$ vs. F, $\mathrm{p}<.002$; A vs. F, $\mathrm{p}<.002$ ).

The Normal rats passively avoided. They spent more time in Segments 4-5-6 than either rats with septal lesions or rats with amygdaloid lesions ( $\mathrm{N}$ vs. $\mathrm{S}, \mathrm{p}<.002 ; \mathrm{N}$ vs. $\mathrm{A}, \mathrm{p}<.05$ ). No differences were found between the Normal and Fornix groups, which might suggest passive avoidance by the animals with lesions in the dorsal fornix. Such was not the case, however, because the Fornix group remained in Segments 4-5-6 just as long as the Septal and Amygdaloid groups, who failed to avoid passively.

Animals with fornix lesions spent the major portion of the 2-min test period actively retreating from the shock-food area. They remained longer in Segments 7-8-9, the segments furthest removed from 


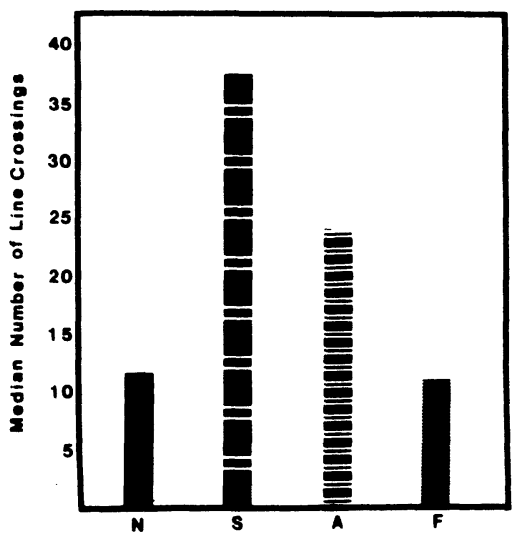

Figure 5. Median number of line crossings for each group during the 2 -min test session.

the food-shock region, than the Normal, Septal, and Amygdaloid groups (F vs. N, p $<.02 ; \mathrm{F}$ vs. S, $\mathrm{p}<.002 ; \mathrm{F}$ vs. $\mathrm{A}, \mathrm{p}<.002)$. Even though rats in the Septal and Amygdaloid groups were seldom observed in Segments 7-8-9, rats with septal lesions spent even fewer seconds in that region of the alley than the rats with amygdaloid removals (S vs. A, $p<.05)$. Neither group, however, differed from the normal subjects.

\section{Activity and Locomotor Pattern}

Figure 5 illustrates the median number of segments traversed (line crossings) by each group during the 2-min test period, thus reflecting their levels of activity. These data were collected by recording the position of the rat at each successive 5-sec interval. A Kruskal-Wallis one-way analysis of variance indicated differences among the groups $(p<.01)$. Between-group comparisons, as tested by MannWhitney U tests, revealed that the Septal group was more active than the Normal group $(p<.05)$; that the Amygdaloid group was more active than the Normal group ( $<<.02)$; that the Septal group was more active than the Fornix group $(p<.02)$; that the Amygdaloid group was more active than the Fornix group ( $p<.002)$; and that no significant differences in activity were found between the Normal and the Fornix groups or between the Septal and the Amygdaloid groups.

Typical patterns of runway position during the test period for all groups are illustrated in Figure 6. Two characteristic locomotor patterns could be discerned for each group, although the two patterns for each group were quite different. In keeping with the outcome reported by Ursin et al. (1969), septal preparations approach the shock locus and fail to avoid passively. Seven out of 12 animals, however, did show oscillations which consisted of rapid retreats to the far end of the apparatus and equally rapid returns to the first-alley segment.

Animals with amygdaloid lesions also failed to avoid passively, but did so in an obviously different manner than the rats with lesions of the septal forebrain. Thus, in the first few seconds of the tests, all septal rats approached the shock locus, but the amygdaloid rats were equally likely to move forward or away from the shock locus. Seven of the preparations then showed relatively slow oscillations from one end of the maze to the other (see Figure 6, Amygdala). Their approaches to the shock locus had an almost casual character, and were not in any sense similar to those of septal preparations except for providing opportunities for failing to avoid passively. Four of the amygdaloid lesioned subjects retreated for approximately $60 \mathrm{sec}$ and then approached the food-shock area. Fornix preparations
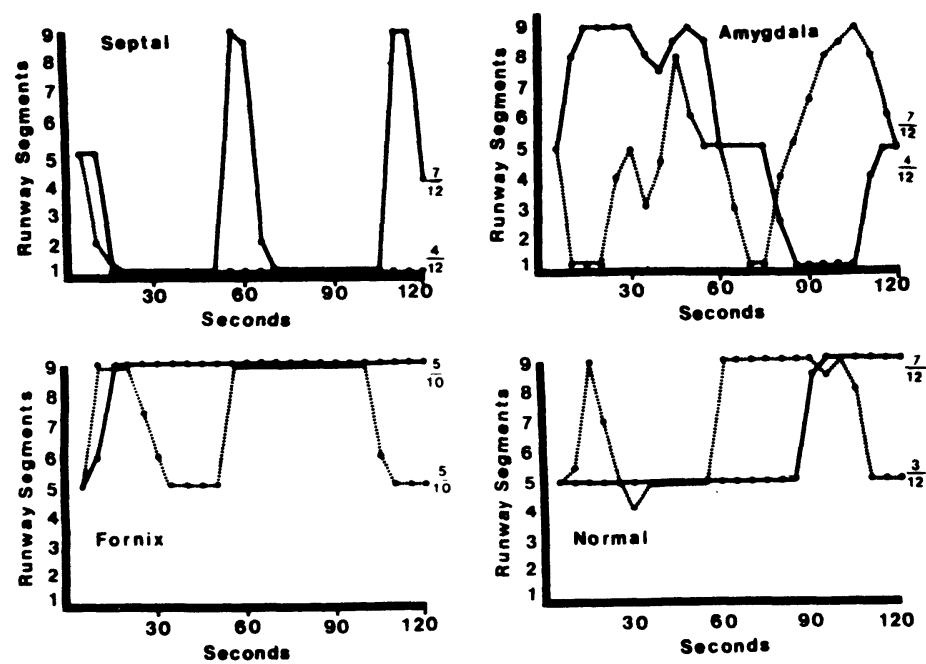

Figure 6. Patterns of locomotion during the 2-min test interval. The graphs illustrate the runway segment location at each successive 5-sec interval for two typical rats in each group. The two ratios at the right of each of the four graphs indicate the number of animals showing one of the two patterns out of the total group population. Only the most typical patterns are shown, thus some animals were not included in the ratios. 
showed withdrawals from the shock locus, and these withdrawals occurred promptly and tended to be persistent (see Figure 6, Fornix). Although some subjects showed occasional returns to the startbox, they did not progress beyond that point.

In keeping with the results obtained by Ursin et al. (1969), normal rats subjected to a PA test of the shock-upon-approach-to-food variety showed a very high likelihood of freezing in place when returned to the startbox (see Figure 6, Normal). Their next most probable response was a retreat from the startbox and the food-shock area, but, in general, retreats were not seen in such subjects until at least $11 \frac{1}{2} \mathrm{~min}$ had elapsed. Only rarely did they move toward the food box, and then never closer than the fourth segment.

\section{DISCUSSION}

Animals with lesions of the septal forebrain showed the PA deficit reported by McCleary (1961) using the typical discrete trial PA procedure and by Ursin et al. (1969) using the continuous time measure of PA in the Maher et al. (1962) apparatus. In spite of the fact that the Septal group in the present study was one of the most active, they spent $60 \%$ of the time in Segments 1-2-3, seldom entering the segments furthest removed from the shock-food area of the runway. Thus, hypermobility, per se, could not account for the dysfunction, for animals in Group A, which were just as active, showed no preference for any of the alley segments. The increased activity in Group S may reflect an inability to inhibit locomotor behavior, but in no way did the hypermobility obscure that group's preference. The subjects with septal lesions appeared to be hyperresponsive to the positively reinforcing stimulus, as other investigators in the past have suggested (Beatty \& Schwartzbaum, 1968; Hothersall, Johnson, \& Collen, 1970). The initial choice of animals with septal lesions was toward the reinforced goal; the majority of their time was spent in that end of the alley; and their pattern of oscillation, which was similar to that reported by Ursin et al. (1969), supports that concept. Group S either immediately entered the shock-food area and remained there for the entire test period or they initially ran to the shock-food area and stayed there for long durations, except for two brief 10 to 20-sec explorations at the opposite end of the runway. Nevertheless, the attractiveness of the positive reinforcement had no effect upon rates of learning the approach task, as compared to normals, nor upon the speed with which they reached the goalbox to consume the reinforcement.

As indicated by the median position data, animals with lesions of the amygdala appeared to avoid passively. However, such was not the case. The subjects in this group distributed their time equally among all segments of the apparatus. No clear deficit in passive avoidance was observed either. Approximately half of the subjects initially approached the foodshock area, and the other half retreated into the neutral alley. This behavior could not be correlated with damage to, or sparing of, specific amygdaloid nuclei. Nevertheless, all subjects in this group showed hypermobility as compared to normal subjects. The increased activity is particularly obvious from inspection of the typical patterns of locomotion during the 2-min test interval (see Figure 6). The patterns of oscillation are reminiscent of the hyperexploratory activity that such preparations characteristically exhibit in large open-field situations (Jonason \& Enloe, 1971). The hyperexploratory behavior can readily obscure such animals approach or avoidance tendencies. This contention is supported by the fact that in the present study, Group A took longer to learn the approach response than normals, and that amygdaloid lesioned subjects in other testing situations fail to avoid aversive stimuli (e.g., Blanchard \& Blanchard, 1972).

Rats with lesions of the fornix longus preferred to actively retreat from the food-shock area. Previous researchers (Fishman \& McCleary, 1966; Kaada, Rasmussen, \& Kveim, 1962; Myhrer \& Kaada, 1975; Van Hoesen, MacDougall, \& Mitchell, 1969) have reported that these preparations have no PA deficit, but discrete trial procedures were employed. In the present study, in which a continuous time measure of PA was used, rats with fornix longus lesions actively retreated rather than remaining passively in the startbox. They spent the major portion of time in the alley segments furthest removed from the shock-food area, and remained there for significantly longer periods of time than the normal control animals. The patterns of oscillation through the runway for the Normal and Fornix groups were quite similar. The major distinction between the two was that the Fornix group immediately retreated to the segments furthest removed from the shock-food area, and that the Normal group did not do so until the last two-thirds of the test session. Since the Normal and Fornix groups also were similar in activity, their preference differences in terms of PA testing could not be attributed to changes in mobility. However, the differences between the two groups might be due to an increased responsiveness to the aversive properties of shock in the rats with fornix longus lesions. A lowered shock threshold could account for the facilitated CAR performance in these preparations as well (Alvarez-Pelaez, 1973; Van Hoesen et al., 1969). Alternatively, since the fornix subjects took longer to learn the approach response before PA 
testing, it is also entirely possible that the incentive properties of the food reinforcement were attenuated in these rats, thus decreasing their approach tendencies to the positive reward. It appears that some change in responsiveness to the motivational properties of the stimuli result from lesions of the fornix longus.

It is somewhat surprising to find that rats with fornix lesions had no PA deficit (present study; Fishman \& McCleary, 1966; Kaada et al., 1962; Myher \& Kaada, 1975; Van Hoesen et al., 1969), in view of the fact that the fornix system is one of the major connections between the septum and the hippocampus, lesions in both of which result in PA deficits (Isaacson \& Wickelgren, 1962; Kaada et al., 1962). In addition, Ursin et al. (1969) reported that rats with septal lesions also tended to retreat actively in the Maher et al. (1962) apparatus, provided that the damage extended into the columns of the fornix. In the present investigation, lesions of the septum did not invade the columns of the fornix, but did damage the fornix longus, dorsal to the medial septum. Since all rats in the Septal group failed the PA task, we conclude that the septal plus fornix longus lesions are not sufficient to protect those subjects from PA disorders.

Additional information about avoidance behavior of animals with limbic system lesions has been obtained by using the Maher et al. (1962) apparatus. Previous research using discrete trial procedures has indicated that both septal and amygdaloid lesions produce PA deficits. The present study suggests that the PA performance of these two preparations is quite different. In the case of animals with septal lesions, we indeed did find a PA dysfunction, which could be attributed to increased incentive properties of the positive reinforcement, rather than a failure to inhibit locomotor responses. Animals with amygdalectomies, however, did not display a clear PA deficit, and the previous suggestion that they have PA dysfunctions could readily be due to their hypermobility, which we observed in the present study. Fornix lesions, on the other hand, have been reported to produce no PA deficit as measured by discrete trial procedures. No PA deficit was observed in the present investigation either. However, enhanced avoidance of the shock-food area was observed. This finding suggests an increased responsiveness to the aversive properties of the shock as opposed to alterations in mobility. Thus, if given an opportunity to retreat actively, rats with fornicotomies will certainly do so, even more quickly than normal animals.

\section{REFERENCES}

Alvarez-Pelaez, R. Effects of fimbria-fornix lesion on avoidance conditioning in the rat. Physiology and Behavior, 1973, 11, 603-607.

Beatty, W. W., \& Schwartzbaum, J. S. Consummatory behavior for sucrose following septal lesions in the rat. Journal of Comparative and Physiological Psychology, 1972, 81, 281-290.

DEGroot, J. The rat forebrain in stereotaxic coordinates. Amsterdam: N. V. Noord-hollandsche Uitgevers Maatschappij, 1959.

Fishman, M., \& McCleary, R. A. A patterned perseverative deficit following fornicotomy in the cat. In: E. Stellar \& J. M. Sprague (Eds.), Progress in physiological psychology (Vol. 1). New York: Academic Press, 1966.

Hothersall, D., Johnson, D. A., \& Collen, A. Fixed-ratio responding of normal and septal rats. Journal of Comparative and Physiological Psychology, 1970, 73, 470-476.

IsAaCson, R. L., \& WICKELGREN, W. O. Hippocampal ablation and passive avoidance. Science, 1962, 138, 1104-1106.

Jonason, K. R., \& Enloe, L. J. Alterations in social behavior following septal and amygdaloid lesions in the rat. Journal of Comparative and Physiological Psychology, 1971, 75, 286-301.

KAADA, B. R. Somato-motor, autonomic and electrocorticographic responses to electrical stimulation of 'rhinencephalic' and other structures in primates, cat and dog. Acta Physiologica Scandanavia, 1951, 24, Supplement 83, 1-258.

KaAda, B. R., Rasmussen, E. W., \& Kveim, O. Impaired acquisition of passive avoidance behavior by subcallosal, septal, hypothalamic, and insular lesions in rats. Journal of Comparative and Physiological Psychology, 1962, 55, 661-670.

MAher, B. A., Elder, S. T., \& Noblin, C. D. A differential investigation of avoidance reduction versus hypermotility following frontal ablation. Journal of Comparative and Physiological Psychology, 1962, 55, 449-454.

MCClEARY, R. A. Response specificity in the behavioral effects of limbic system lesions in the cat. Journal of Comparative and Physiological Psychology, 1961, 54, 605-613.

MeYer, P. M., \& MEYER, D. R. Producing brain lesions by aspiration methods. In: $\mathrm{R}$. Myers (Ed.), Methods in neuropsychology. London: Academic Press, 1972.

MYHRER, T., \& KAADA, B. R. Locomotor, avoidance and maze behavior in rats with dorsal fornix transected. Physiology and behavior, 1975, 14, 847-853.

Pellegrino, L. Amygdaloid lesions and behavioral inhibition in the rat. Journal of Comparative and Physiological Psychology, 1968, 65, 483-491.

Pellegrino, L., \& Cushman, A. J. A stereotaxic atlas of the rat brain. New York: Appleton-Century-Crofts, 1967.

Ursin, H., LINCK, P., \& MCClEARY, R. A. Spatial differentiation of avoidance deficit following septal and cingulate lesions. Journal of Comparative and Physiological Psychology, 1969, 68, 74-79.

Van Hoesen, G. W., MacDougall, J. M., \& Mrtchell, J. C. Anatomical specificity of septal projections in active and passive avoidance behavior. Journal of Comparative and Physiological Psychology, 1969, 68, 80-89.

(Received for publication January 30, 1976; revision accepted March 19, 1976.) 